\section{Urinary incontinence: quality of life and psychological aspects}

\section{Vito Leanza, ${ }^{1}$ Alessia Passanisi, ${ }^{2}$ Gianluca Leanza'}

'Surgery Department, Urogynaecologic Unit, University of Catania; ${ }^{2}$ Faculty of Human and Social Sciences, University Kore of Enna, Italy

\section{Abstract}

The objective of this study was to evaluate the impact of female urinary incontinence (UI) on quality of life. The method of research is based on a literature search on PubMed, Cochrane library and relevant articles from 1977 to 2012. Forty-eight works were found. Literature showed that UI affects a large percentage of the aged out patients. Women experience UI because of many reasons such as childbirth, menopause and previous gynaecologic surgery. Incontinence is to be treated as it impacts physiological and psychological aspects of patient's life. Treatments include medical, physical (rehabilitation) and surgical approaches. Measures for assessment are made up by specific and non-specific questionnaires. Evaluation of female incontinence must take into account patients with and without medical treatment.

Every sort of therapy has to consider the psychological impact too. In current literature depression, anxiety, shame and decreed selfefficacy resulted as the most important factors involving women with UI.

\section{Introduction}

Urinary incontinence (UI), according to the International Continence Society (ICS) is $a$ complaint of any involuntary leakage of urine ${ }^{1}$ and a common health problem for women. There are lots of different kinds of urinary incontinence, including stress, urge, mixed, and overflow incontinence. Stress incontinence (SUI) is involuntary leakage from effort, exertion, sneezing or coughing. It is usually linked to an increased urethral mobility or intrinsic sphincter deficiency. Urge UI is involuntary leakage accompanied or immediately proceeded by urgency, and it usually indicates detrusor overactivity. Mixed incontinence (MUI) is the complaint of involuntary leakage associated with urgency and physical stress. A less common type of urinary incontinence is overflow incontinence, which is associated with overdistension of the bladder usually caused by obstruction (severe pelvic organ prolapse) or a neurological condition (spinal cord injury). ${ }^{2}$

SUI increases with age. $17-55 \%$ of old women report having experienced urinary incontinence, compared with $12-42 \%$ of middle age. ${ }^{3}$ Women experience SUI because of many reasons such as pregnancy and previous gynaecologic surgery. SUI is often associated with obesity as well. Lots of factors are either inevitable (aging) or socially desirable (vaginal delivery). ${ }^{4-6}$ Consequently SUI is considered as a normal condition. ${ }^{7}$ Furthermore, owing to embarrassment and shame SUI exists as a condition of silence. ${ }^{8-10}$ Moreover SUI might have serious consequences such as depression, anxiety and low quality of life. ${ }^{11}$

\section{Method of research}

A literature research has been carried on in the main databases (e.g. PubMed, Cochrane library) and relevant articles from 1977 to 2012 were selected.

Exploring the theoretical definitions of UI in current literature, this article analyzes the multifaceted physiological and psychological issues involved in the examined pathology, as well as the instruments used for the assessment of quality of life (QoL).

\section{Results}

Forty-eight works were found. Women with UI are more likely to report a poorer quality of life. Shame triggered by leakage and odor can impair a woman's ability to participate in everyday activities, social life, sexual performance and lead to relational troubles. ${ }^{12-15}$ Many woman struggling with SUI do not report their symptoms to their physicians and often keep the associated inconvenience and discomfort for many years, possibly because they are embarrassed. Others are not worried about their condition to seek treatment. ${ }^{16}$

Shame, ${ }^{17}$ depression and anxiety have been suggested to co-occur in incontinent women. ${ }^{18}$ Various researchers have found a relation between incontinence and depression..$^{19,20}$ It is not clear if the incontinence causes depression or vice versa. However, it is clear that a relationship exists. Bandura ${ }^{21}$ claimed that depression will occur when either self-efficacy (the belief a person has in his or her ability to perform specific behaviors) or outcome expectancy is low. Depression is described as an alteration in mood ranging from a mild sadness to overwhelming despair. It is characterized by feelings of sadness, emptiness, dissatis-
Correspondence: Alessia Passanisi, Facoltà di Scienze Umane e Sociali, Università di Enna "Kore", Cittadella Universitaria, 94100 Enna, Italy.

E-mail: alessiapassanisi@gmail.com

Key words: quality of life, self-efficacy, urinary incontinence, instruments.

Received for publication: 22 January 2013.

Revision received: Not requested.

Accepted for publication: 8 August 2013.

This work is licensed under a Creative Commons Attribution NonCommercial 3.0 License (CC BYNC 3.0).

CC Copyright V. Leanza et al., 2013

Licensee PAGEPress, Italy

Urogynaecologia 2013; 27:e3

doi:10.4081/uij.2013.e3

faction, lowered self-esteem, inactivity, and self-depreciation. ${ }^{22}$ Depression may be elicited by personal perception of cognition, ${ }^{23}$ negative events and physiological states. Depression takes place when a person doesn't feel able to control the outcome of an action (external locus of control). This perception affects the choice of activities to engage in and the invested effort. Self-evaluation of events is often biased by those with low self-efficacy, consequently depression is likely to occur when outcome expectancy is high and performance expectation is low. ${ }^{24}$ The effect of self-efficacy on QoL has been investigated in several studies of health related behaviors. Self-efficacy and quality of life are positively whereas depression and self-efficacy are negatively related. Moreover, Leanza and Passanisi ${ }^{25}$ found that stress and low negative affective self-efficacy happen among women suffering from SUI. This might suggest the idea that distress and scarce self-efficacy might not only be the predictors but also a consequence of this urogynecological pathology. Since all the types of incontinence (SUI, UI and MUI) highly affect QoL, behavioral techniques and rehabilitation of the pelvic floor are strongly recommended. ${ }^{26}$ In addition, Swati et al. ${ }^{27}$ found that tension-free vaginal tape procedure significantly improves the overall sex lives of women with SUI: orgasm incontinence, penetration incontinence, post-coital infections, anxiety and avoidance of sex are all reduced. Symptoms and impact of incontinence have to be properly assessed and recorded before and after therapy. ${ }^{28}$ Among the various health related quality of life measures used in literature, two kinds of instruments are available: specific and non specific questionnaires.

The most used specific questionnaires include the following: the Urinary 
Incontinence Short Form (ICIQ), the Bristol Female Lower Urinary Tract Symptoms Questionnaire (BFLUTS), the King's Health Questionnaire (KHQ), the Incontinence Impact Questionnaire (IIQ), the Urinary Incontinence Severity Score (UISS), the Urinary Incontinence Specific Quality of Life Instrument (I-QOL, ICIQ-UIQOL) and the Geriatric Self-Efficacy index for Urinary Incontinence (GSE-UI).

The ICIQ Short Form is a four-item instrument aimed at assessing the symptoms of UI and their impact on the quality of life of men and women. ${ }^{29}$ The first three items are scored and the fourth is an unscored self-diagnostic item. Scoring ranges from 0 to 21 for a summed score for the first three items; a higher score indicates worse symptoms/higher impact on QoL. The ICIQ short form for incontinence has recently been subject to considerable psychometric testing. A developmental version of the questionnaire was produced following systematic literature review. This questionnaire is available in 38 languages.

BFLUTS $^{30}$ [also known as ICI Questionnaire-Female Lower Urinary Tract Symptoms (ICIQ-FLUTS)] was created in the United Kingdom to assess the impact of female UI and other lower urinary tract symptoms on QoL. This questionnaire was developed from the longer questionnaire covering the occurrence and bother some ness of symptoms relating to incontinence and other lower urinary tract symptoms for women. This measure is available in 10 languages. A scored short form of the questionnaire is also available.

$\mathrm{KHQ}^{31}$ was developed at King's College Hospital in London as part of a large longitudinal study on quality of life. The questionnaire is made of three parts. The first section contains two items measuring general health and overall health related to urinary symptoms. The second section includes 19 questions divided into seven factors related to QoL: incontinence impact, role limitations, physical limitations, social limitations, personal relationships, emotions, sleep and energy, severity coping measures, general health perception, and symptom severity. The third section of the questionnaire consists of 11 questions measuring the bother or impact of urinary symptoms on QoL. High scores indicate a worse quality of life. This instrument is available in 45 languages.

IIQ $^{32}$ was developed in the United States to assess the psychosocial impact of urinary incontinence in women and consists of 30 items. Scores are obtained overall or for four subscales: physical activity, travel, social relationships, and emotional health. The IIQ has been found to have good psychometric properties across a range of studies. There is also a short form of the IIQ, the IIQ-7, which consists of seven questions with the same psychomet- ric characteristics of the long form. Both questionnaires are available in English and Turkish.

UISS $^{33}$ was developed by the Finnish Gynecological Society's urogynecologic working group in 1992, and consists of 10 items divided into 3 clusters; social interactions, physical activities and sexual function, with a visual analogue scale for subjective burden of incontinence on a $100 \mathrm{~mm}$ scale. It has been widely used in clinical practice.

I-QOL, ICIQ-UIQOL ${ }^{34,35}$ is a 22 -item measure developed to assess the quality of life of women with UI. The instrument consists of three subscale: avoidance and limiting behaviors, psychosocial impacts, and social embarrassment. Responses for all items are scored on a 5-point scale where a higher score indicates better quality of life. This questionnaire is available in 35 languages.

GSE-UI ${ }^{36}$ is a new instrument to measure one of the psychological factors potentially underlying continence statuses: confidence or self-efficacy for preventing unwanted urine loss. Self-efficacy, the belief a person has in his or her ability to perform specific behaviors, has been shown to be an important factor for improving outcomes in other geriatric conditions, such as falls. ${ }^{37}$

The non-specific questionnaires include the locus of control of behavior (LCB), the stress psychological measure (MSP) and the perceived negative affective self-efficacy scale (PNASES).

$\mathrm{LCB}^{38}$ was applied for the assessment of incontinence. This questionnaire consists of 17 items with a rating scale ranging from 0 to 5. Seven items $(1,5,7,8,13,15$, and 16) are aimed at assessing the inner control, whereas the others refer to the external control. The indicative value of the 17 answers consists into the sum of the items score over the external control plus the inverted scores $(5=0$ $0=5$ ) of the questions relevant to the inner control.

MSP is a 49 item-questionnaire self-report developed by Tessier et al. ${ }^{39}$ (Mesure du Stress Psychologique, University Laval of Quebec), and adapted to an Italian sample by Di Nuovo, Rispoli and Genta. ${ }^{40}$ Scoring includes an overall score and 6 clusters of items: i) loss of control and irritability (11-22-32-35-36-46); ii) psycho-physiological sensation (16-25-34-40); iii) sense of effort and confusion (33-37-41$42)$; iv) depressive anxiety (6-13-15-29); v) pains and physical problems (12-14-28); vi) hyperactivity and accelerated behaviors (2644-45).

PNASES $^{41}$ is an 8 item measure, developed by Caprara et al., describing circumstances in which people may experiment frustration and discouragement. Perceived self-efficacy ${ }^{42,43}$ is concerned with people's confidence in their capacities to cope with events that affect their lives, showing high control.

Self-efficacy has been shown to be an important factor for improving QoL and reducing stress. As UI commonly occurs in many old women, identification of pathology, both clinically and psychologically, may help to reduce stress and other negative consequences avoiding the increasing number of healthcare visits annually. ${ }^{25,44}$

When UI is properly treated with physical, psychological and surgical approaches, patients might change the expectance of life. Further fore it happens when women are able to face rather than avoid the problem. ${ }^{45-47}$

\section{Conclusions}

Although a number of UI measures exist, there is substantial evidence that they are rarely used in clinical practice. ${ }^{48}$ It is essential that the warning signs of UI and their psychological impact may be properly assessed. The most evident (overt) and, above all, the most hidden (covert) symptoms, negatively affect QoL regarding physical, psychological problems and interfere with both sexual and social life.

\section{References}

1. Abrams P, Cardozo L, Fall M, et al. The standardization of terminology of lower urinary tract function: Report from the standardization sub-committee of the International Continence Society. Urology 2003;61:37-49.

2. Holroyd-Leduc JM, Straus SE. Management of urinary incontinence in women. JAMA 2004;291:986-95.

3. Thom D. Variation in estimates of urinary incontinence prevalence in the community: effects of differences in definition, population characteristics, and study type. J Am Geriatr Soc 1998;46:473-80.

4. Hannestad YS, Rortveit G, Sandvik H, Hunskaar S. A community based epidemiological survey of female urinary incontinence: the Norwegian EPI-NCONT study. Epidemiology of incontinence in the country of Nord-Trondelag. J Clin Epidemiol 2000;53:1150-7.

5. Minassian VA, Drutz HP, Al-Badr A. Urinary incontinence as a worldwide problem. Int J Gynecol Obstet 2003;82:327-38.

6. Peyrat L, Haillot 0, Bruyere F, et al. Prevalence and risk factors of urinary incontinence in young and middle-aged women. BJU Int 2002;89:61-6.

7. Peake S, Manderson L, Potts H. Part and parcel of being a woman: female urinary 
incontinence and constructions of control. Med Anthropol Q 1999;13:267-85.

8. Bradway C, Barg F. Developing a cultural model for long-term female urinary incontinence. Soc Sci Med 2006;63:3150-61.

9. Brittain KR, Shaw C. The social consequences of living with and dealing with incontinence - a carer's perspective. Social Sci Med 2007;65:1274-83.

10. Horrocks S, Somerset M, Stoddart H, Peters TJ. What prevents older people from seeking treatment for urinary incontinence? A qualitative explo-ration of barriers to the use of community continence services. Fam Pract 2004;21:689-96.

11. Hemachandra NN, Rajapak LC, Manderson L. A usual occurrence: stress incontinence among reproductive aged women in Sri Lanka. Social Sci Med 2009;69:1395-401.

12. Berglund AL, Eisemann M, Lalos A, Lalos 0 . Social adjustment and spouse relationships among women with stress incontinence before and after surgical treatment. Social Sci Med 1996;42:1537-44.

13. Bradway C, Barg F. Developing a cultural model for long-term female urinary incontinence. Social Sci Med 2006;63:3150-61.

14. Fultz NH, Burgio K, Diokno AC, et al. Burden of stress urinary incontinence for community-dwelling women. Am J Obstet Gynecol 2003;189:1275-82.

15. Margalith I, Gillon G, Gordon D. Urinary incontinence in women under 65: quality of life, stress related to incontinence and patterns of seeking health care. Qual Life Res 2004;13:1381-90.

16. Fantl JA, Harkins SW, Wyman JF, et al. Fluid loss quantification test in women with urinary incontinence: a test-retest analysis. Obstet Gynecol 1987;70:739-43.

17. Schimmenti A. Unveiling the hidden self: developmental trauma and pathological shame. Psychodyn Pract 2012;18:195-211.

18. Burgio KL, Whitehead WE, Engel BT. Urinary incontinence in the elderly: bladder-sphincter biofeedback and toilet training skills. Ann Inter Med 1985;104:507-15.

19. Meade-D'Alisera P, Merriweather T, Wentland M, et al. Depressive symptoms in women with urinary incontinence: a prospective study. Urol Nurs 2001;21:397400.

20. Zorn BH, Montgomery H, Poeper K, et al. Urinary incontinence and depression. $\mathrm{J}$ Urol 1999;162:82-4.

21. Bandura A. Self-efficacy: toward a unifying theory of behavioral change. Psychol Rev 1977;84:194-215.

22. Lewis S, Grainger RD. Manual of psychosocial nursing interventions: promoting mental health in medical-surgical settings. The patient with depression.
Philadelphia, PA: W.B. Saunders Co.; 1989.

23. Hampton JA, Passanisi A, Jonsson M. The modifier effect and property mutability. J Mem Language 2011;64:233-48.

24. Bandura A. Social foundations of theory and action: a social cognitive theory. Englewood Cliffs, NJ: Prentice-Hall; 1986.

25. Leanza V, Passanisi A, Leanza G. A specific application of two psychological measures on female urinary incontinence: perceived negative affective self-efficacy scale and stress psychological measure. In: Proceedings of the 21st AIUG National Congress, 2011 Nov 6-8, Torino, Italy. UIJ 2011;25 suppl 2:41-8.

26. Leanza V, Accardi M. Efficacy of perineal education and physiokinesitherapy on stress urinary incontinence during and after pregnancy. Int Urogynecol J 2008;298.

27. Jha S, Radley S, Farkas A, Jones G. The impact of TVT on sexual function. Int Urogynecol J 2009;20:165-9.

28. Leanza V, Pisapia Cioffi G, Belfiore T, Biondi R. Urinary incontinence (UI): psychological impact (PI) and quality of life (QoL). In: Proceedings of the 19th AIUG National Congress, 2009 Nov 22-24, Napoli, Italy. UIJ 2009;23 suppl 2:39-46.

29. Avery K, Donovan J, Peters TJ, et al. ICIQ: a brief and robust measure for evaluating the symptoms and impact of urinary incontinence. Neurourol Urodyn 2004;23:32230 .

30. Jackson S, Donovan J, Brookes S, et al. The Bristol female lower urinary tract symptoms questionnaire: development and psychometric testing. $\mathrm{Br} \mathrm{J}$ Urol 1996;77:805-12.

31. Kelleher CJ, Cardozo LD, Khullar V, Salvatore S. A new questionnaire to assess the quality of life of urinary incontinent women. Br J Obstet Gynaecol 1997;104: 1374-9.

32. Shumaker SA, Wyman JF, Uebersax JS, et al. Health-related quality of life measures for women with urinary incontinence: the incontinence impact questionnaire and the urogenital distress inventory. Continence Program in Women (CPW) Research Group. Qual Life Res 1994;3:291306.

33. Stach-Lempinem B, Kujansuu E, Laippala P, Metsanoja R. Visual analogue scale, urinary incontinence severity scale and $15 \mathrm{D}$ psychometric testing of three different health-related quality of life instruments for urinary incontinent women. Scand J Urol Nephrol 2001;35:476-83.

34. Wagner TH, Patrick DL, Bavendam TG, et al. Quality of life of persons with urinary incontinence: developing a new measure.
Urol 1996;47:67-71.

35. Patrick DL, Martin ML, Bushnell DM, et al. Quality of life of women with urinary inconti-nence: further development of the incontinence quality of life instrument (IQOL). Urology 1999;53:71-6.

36. Tannenbaum C, Brouillette J, Michaud J, et al. Responsiveness and clinical utility of the geriatric self-efficacy index for urinary incontinence. JAGS 2009;57:470-5.

37. Carroll DL. The importance of self-efficacy expectations in elderly patients recovering from coronary artery bypass surgery. Heart Lung 1995;24:50-9.

38. Craig A, Franklin J, Andrews G. A scale to measure locus of control of behavior. Br J Med Psychol 1984;57:173-80.

39. Lemyre L, Tessier R, Fillion L. Mesure du stress psychologique (MSP). Brossard, Quebec: Editions Behaviora, Inc.; 1990.

40. Di Nuovo S, Rispoli L, Magenta E. Misurare lo stress. Il test M.S.P. e altri strumenti per una valutazione integrata. Milano: Franco Angeli; 2000.

41. Caprara GV. Evaluation of self-efficacy. Trento: Erickson; 2000.

42. Bandura A. Self-efficacy mechanism. In: Madden J, ed. Physiological activation and health-promoting behavior. Neurobiology of learning, emotion and affect, IV Ed. New York: Raven; 1991. pp 229-270.

43. Bandura A. Self-regulation of motivation through anticipatory and self-regulatory mechanisms. In: Dienstbier RA, ed. Perspectives on motivation: Nebraska symposium on motivation. Lincoln: University of Nebraska Press; 1991b. pp $38,69-164$.

44. Milsom I, Kaplan SA, Coyne KS, et al. Effect of bothersome overactive bladder symptoms on health-related quality of life, anxiety, depression, and treatment seeking in the United States: results from EpiLUTS. Urology 2012;80:90-6.

45. Leanza V. Tension-free mini-invasive Antiincontinence procedures: comparison among three main pathways. Open Women Health J 2012;6:30-5.

46. Leanza V. Prepubic TICT: a new approach to solve both incontinence and cystocele. Urovirt 2005;9. Available from: http://www. urovirt.org.br

47. Leanza V, Dati S, Gasbarro N, Accardi M. Two mininvasive procedures for anterior compartment: r-TICT AND p-TICT. In: Proceedings of the 18th AIUG National Congress, 2008 Nov 13-15, Italy. UIJ 2008;22 suppl 2:120-5.

48. Smith GL, Kobashi KC. Validated instruments in the evaluation and treatment outcomes of stress urinary incontinence in women. Curr Urol Rep 2011;12:381-6. 